\title{
UMA INTRODUÇÁO À ANÁLISE ECONÔMICA DO DIREITO
}

AN INTRODUCTION TO ECONOMIC ANALYSIS OF LAW

\author{
ROGERIO BORBA ${ }^{1}$
}

RAFAEl DE OLIVEIRA MÔNACO ${ }^{2}$

\section{RESUMO}

O presente artigo tem por objeto tratar dos aspectos introdutórios da Análise Econômica do Direito (AED). Para o alcance do objetivo a pesquisa iniciou pela interação entre as ciências do Direito e da Economia, suas diferenças e convergências. Em seguida se tratou da origem do movimento, passando às premissas metodológicas da teoria econômica calcada na escassez de recursos, na racionalidade maximizadora, na estrutura de incentivos e na questão da eficiência. A pesquisa converge para a demonstração de necessidade de diálogo e cooperação entre as disciplinas do Direito e Economia. Conclui-se que a AED, em seu viés pragmático e consequencialista, auxilia o jurista a compreender a aplicação da norma jurídica (sentido descritivo) fornecendo as chaves de compreensão das escolhas feitas pelo legislador sobre os diferentes temas visando o aprimoramento da legislação (sentido preditivo). 0 artigo se insere no ramo das Ciências Jurídicas e Econômicas, na área do Direito Econômico, sendo analisada em uma perspectiva holística. A metodologia adotada foi a revisão bibliográfica e documental a partir de uma análise qualitativa.

PALAVRAS-CHAVE: Direito. Economia. Análise Econômica do Direito.

\section{ABSTRACT}

The purpose of this article is to deal with the introductory aspects of Economic Analysis of Law (AED). To reach the objective, the research started by the interaction between the sciences of Law and Economics, their differences and convergences. Then it was about the origin of the movement, passing to the methodological premises of the economic theory based on the scarcity of resources, the maximizing rationality, the incentive structure and the question of efficiency. The research converges to demonstrate the need for dialogue and cooperation between the disciplines of Law and Economics. It is concluded that the AED, in its pragmatic and consequentialist bias, helps the jurist to understand the application of the legal norm (descriptive sense) providing the keys for understanding the choices made by the legislator on the different themes aiming at the improvement of legislation (predictive sense). The article is inserted in the branch of Legal, Social and Environmental Sciences, in the areas of Environmental Law, Water Law and Civil Procedural Law, being analyzed in a holistic perspective. The methodology adopted was bibliographic and documentary, in a qualitative analises.

KEYSWORDS: Law. Economy. Economic Analysis of Law.

1 Doutor em sociologia. Mestre em Direito. Professor Permanente do PPGD da UVA. rogerioborba@gmail.com.

2 Mestrando em Direito. UCAM / EMERJ. rafaelomonaco@gmail.com. 


\section{INTRODUÇÁO}

O Direito, enquanto modo de ordenação social, nos sistemas de tradição romano-germânica, tradicionalmente é concebido tendo por base o conceito de sanção.

Na coercibilidade, na subsunção do fato à norma e na metodologia pura (COELHO, 2001, Pag. 02) ${ }^{3}$, sem a contaminação de outros saberes, que o Direito, enquanto ciência, se revelava.

No entanto, a medida que a complexidade do fenômeno social crescia, notadamente a partir da primeira metade do século XX, o positivismo jurídico entrava em crise. Não se podia mais encerrar a norma jurídica ao texto legal, nem confundir a lei com o próprio Direito. 0 formalismo jurídico de perfil hermético, legalista e estéril não atendia aos reclames da sociedade.

O pluralismo social exigia novos conhecimentos que a ciência do direito, por si só, era incapaz de oferecer. Reclamavam-se, pois, novas respostas para velhos problemas. Surgem, assim, novos arquétipos como movimento de reação ao chamado juspositivismo.

Ao contrário do sistema europeu que caminhou com ênfase na principiologia constitucional, o modelo norte-americano voltou-se para uma visão aproximativa da realidade social ou pragmática do Direito, trabalhando, ao invés de valores abstratos, respostas concretas, dotando o Direito de um conhecimento sincrético ou interdisciplinar calcado em novas ferramentas interpretativas advindas da Economia (GICO JÚNIOR, 2012, p. 07) ${ }^{4}$.

É nesse contexto, então, que se desenvolve a teoria econômica do direito, marcada pela interdisciplinaridade e plasmada em um uma nova metodologia. Emprega-se o instrumental econômico, teórico e empírico, visando aperfeiçoar a elaboração legislativa, a interpretação doutrinária e a aplicação jurisprudencial das normas jurídicas com base na análise dos resultados e consequências. Inaugura-se, portanto, um novo modelo formatado pela chamada jus economia.

Entretanto, o diálogo entre o Direito e a Economia nem sempre foi facilitado. Ao revés, em razão do isolamento científico, da especialização acadêmica e da diversidade de objetos, essa ponte, por muito tempo deixou de ser cruzada. Havia, nessa colocação, um certo preconceito de ambas as partes, o que causava grande ruído entre o intercâmbio de conhe-

3 Tal era a influência de Hans Kelsen, que sob a coluna do positivismo jurídico, defendia uma concepção pura do Direito, tendo por objeto, exclusivamente, a norma jurídica sancionatória de um lado, e o valor de neutralidade de outro amparada no critério único de validade, afastando-se, assim, dado o caráter de cientificidade do Direito, das questões relativas à ética, moral, política, sociologia e, também, da economia. "O cientista do direito deve ocupar-se exclusivamente da norma posta. Os fatores interferentes na produção da norma, bem como os valores que nela se encerram são rigorosamente estranhos ao objeto da ciência jurídica. Caberia à sociologia, psicologia, ética ou teoria política o exame da conexão entre o direito e os fatos próprios ao objeto de cada disciplina. A teoria pura não nega a conexão, mas a sua importância ou mesmo pertinência no estudo do conteúdo da norma jurídica. Por outro lado, o conhecimento jurídico para ser científico deve ser neutro, no sentido de que não pode emitir qualquer juízo de valor acerca da opção adotada pelo órgão competente para a edição da norma jurídica.

4 "No realismo jurídico norte-americano, a reação ao juspositivismo resultou em um clamor pela interdisciplinaridade com as demais ciências para aproximar direito da realidade social, afastando-se de seu formalismo estéril. Esse movimento acabou por gerar várias escolas de pensamento jurídico interdisciplinares, não necessariamente convergentes, que tentavam enxergar o mundo de forma mais realista e pragmática pela ciência, como a Análise Econômica do Direito e os Estudos Críticos do Direito (Critical Legal Studies), entre outros movimentos. Já nos países de tradição europeia-continental, inclusive no Brasil, uma das reações tardias ao juspositivismo foi o neoconstitucionalismo, que se propõe a denunciar a incapacidade de o raciocínio lógico-formal lidar com questões valorativamente controvertidas, para as quais não há uma única resposta e retoma a posição segundo a qual não seria possível uma referência a direito sem uma conotação valorativa. 
cimentos (PINHEIRO; SADDI, 2005, p. 04). Vários são os fatores que contribuíram para o afastamento dessas ciências.

É possível falar que enquanto o Direito é discurso (linguagem retórica), a Economia é matemática (linguagem econométrica); o Direito possui como valor o ideal de Justiça (abstração), já a Economia almeja resultados eficazes (concretude); Direito é dogmático e hermético (sistema fechado), ao contrário da Economia que é empírica (sistema aberto); o Direito é legalista (formal), mas a Economia é utilitária (pragmática); o Direito opera no mundo do dever ser (sentido prescritivo), no entanto a Economia atua no mundo do ser (sentido descritivo) (SALAMA, 2017, p. 12).

No entanto, é do passado esse antagonismo metodológico, uma vez que ambas as ciências lidam com problemas de organização, estabilidade e eficiência do sistema. Ademais, não existe um direito que não reflita um custo econômico, bem como não funciona um sistema econômico despido de instituições jurídicas que lhe promovam uma roupagem e que garantam o cumprimento das transações (NUSDEO, 2008, p 39) ${ }^{5}$. Correspondem, pois, ambos os saberes, como o verso e o reverso da medalha.

Logo, atualmente, não tem razão de ser o aprisionamento desses dois conhecimentos científicos. Direito e Economia andam juntas, de mãos dadas, são campos que se cruzam e se interpenetram. Há, pois, uma interação dialética, com recíproca influência, entre o econômico e o jurídico, não sendo possível conceber este como uma superestrutura ideológica daquela, nem tampouco reduzir àquela como fonte exclusiva das normas jurídicas.

Tanto isso é verdade que a Constituição da República consagrou todo um capítulo a respeito da Ordem Econômica demonstrando a perfeita sintonia que existe entre tais ciências, transformando o fenômeno econômico em objeto juridicamente apreciável, tal qual o toque de Midas (REALE JUNIOR, 2002, p. 29) ${ }^{6}$.

Com efeito, é fora de dúvida a importância de ambas as disciplinas para a ordenação social, já que o relacionamento entre o Direito e a Economia sempre foi um romance que fez tremer as bases do mundo civilizado, desde os primórdios da história humana (LEWIS, 2005, p. 23).

É preciso, assim, compreender ambas as vertentes dentro de uma perspectiva aproximativa do conhecimento científico sem confinamentos estéreis, tendo em vista a reciprocidade de efeitos que dessa relação deriva.

Mostra-se, pois, íntima a conexão, de modo que, mais do que confronto, é preciso, antes de tudo, cooperação.

O artigo se insere no ramo das Ciências Jurídicas e Econômicas, na área do Direito Econômico, sendo analisada em uma perspectiva holística.

5 "Economia e Direito são indissociáveis, pois as relações básicas estabelecidas pela sociedade para o emprego dos recursos escassos são de caráter instrumental, vale dizer, jurídico. Por outro lado, as necessidades econômicas influenciam a organização institucional e a feitura das leis. De qualquer maneira, não existe fenômeno econômico não inserido em um nicho institucional".

6 "Diríamos que o Direito é como o rei Midas. Se na lenda grega esse monarca convertia em ouro tudo aquilo em que tocava, aniquilando-se na sua própria riqueza, o Direito, não por castigo, mas por destinação ética, converte em jurídico tudo aquilo em que toca, para dar-Ihe condições de realizabilidade garantida, em harmonia com os demais valores sociais". 
Apresenta-se, então o seguinte questionamento: Há relação científica entre Direito e Economia? A hipótese trabalhada não só reconhece a relação, como prevê sua articulação como um ramo científico novo.

Objetiva-se, com isso, avaliar a forma de relação entre estes dois saberes, desenvolvendo-se uma nova linha científica. A metodologia adotada foi a bibliográfica e documental, em uma análise qualitativa. A relevância acadêmica da pesquisa se demonstra no sentido de contribuir para o reconhecimento / consolidação do Direito Econômico enquanto ramo autônomo da ciência.

\section{ORIGEM HISTÓRICA}

Esse movimento deita raízes históricas no empirismo Humano (BITTAR, 2019, p. 85) ${ }^{7}$, no pragmatismo filosófico (CHAUI, 2000, p. 132) ${ }^{8}$ e se reflete de modo claro no realismo jurídico (FONTES, 2014, p. 86-87) ${ }^{9}$ (GODOY, 2012) ${ }^{10}$, rejeitando os conceitos metafísicos de Justiça para buscar nos critérios de experimentação, utilidade, consequencialismo, bem-estar social e eficiência os pilares dessa novel escola.

Para Richard Posner, considerado um dos pais fundadores dessa corrente de pensamento, na Escola Americana de Chicago, a partir da década de 1970, a análise econômica do direito corresponde ao mais importante desenvolvimento do pensamento jurídico do último quarto de século, tendo a Economia se espalhado para um crescente gama de questões jurídicas a ela não vinculadas tradicionalmente (POSNER, 1986, p. 17).

É certo que, quando se fala em análise econômica mostra-se intuitivo pensar em temas de grande repercussão nacional, como taxa de juros, inflação, políticas cambiais, poupanças e mercados. Em síntese, se pensa em dinheiro. Isso, contudo, é meia verdade. A ciência econômica não se ocupa exclusivamente de questões pecuniárias, vai muito além.

A moderna economia ultrapassou os limites da produção e distribuição de bens e serviços para se debruçar sobre o comportamento humano não mercadológico, no processo

7 "A filosofia de David Hume tem seus alicerces baseados na experiência prática, que figura como a grande matriz do conhecimento, se enquadrando nas filosofias empiristas inglesa e escocesa, afastando-se do racionalismo jusnaturalista imperante'.

8 Para os filósofos empiristas, a verdade, além de ser sempre de fato deve ser obtida por experimentação, tendo como a sua eficácia ou utilidade prática. 0 conhecimento é tido como verdadeiro não só quando explica um fato, mas sobretudo quando permite observar consequências práticas e aplicáveis.

9 "O realismo ou pragmatismo jurídico é a corrente da jusfilosofia segundo a qual o direito, pelo menos o direito válido, é aquele efetivamente observado e aplicado em dada sociedade. Essa corrente afasta-se tanto do jusnaturalismo quanto do positivismo normativo. (...). O realismo jurídico é influenciado pelo pragmatismo filosófico e também pelo utilitarismo, recomendando que o juiz se preocupe sobretudo com as consequências práticas de suas decisões".

10 É substancial a crítica realizada a respeito do desconhecimento dos juristas, acerca do realismo jurídico, nos países de matriz positivista. Afirma o autor que: "Os realistas abandonaram a metafísica e os construídos românticos de direito natural, em favor do pragmatismo, da utilidade prática, da atuação fática. 0 realismo jurídico norte-americano relaciona-se com o pragmatismo, bem como com alguns núcleos expressivos do pensamento jurídico contemporâneo, a exemplo do movimento law and economics (Direito e Economia) e do critical legal studies (teoria crítica do Direito). Pouco conhecido no Brasil, porque confundido com tradição jurídica supostamente refratária à nossa, o realismo jurídico norte-americano não é assunto que tem preocupado a indagação jusfilosófica brasileira, que já foi vítima de monoglossia crônica e patológica, centrada em traduções de textos europeus. Somos ainda reféns da filosofia analítica, da metafísica alemã, do fundacionalismo francês e de um incipiente constitucionalismo português. É lugar comum à associação do entorno cultural dos Estados Unidos com o imperialismo que matiza o capitalismo daquele país e com produtos midiáticos de consumo. Por isso, o descaso para com um pensamento substancialmente muito denso, que precisamos de certa forma estudar". 
de tomada de decisões, em um mundo racional em que os recursos são limitados frente às necessidades pessoais e onde as pessoas visam promover o seu próprio interesse.

Segundo o conceito de Lionel Robbins (2014), a economia deve ser compreendida, então, como "a ciência que estuda o comportamento humano como uma relação entre fins e meios escassos que possuem usos alternativos".

Decorre daí o acerto da frase de Edmund Burke (2019) pela qual "a economia é uma virtude distributiva e consiste não em poupar, mas em escolher".

Logo, se as condutas humanas são passíveis de escolhas para o uso de recursos escassos de forma alternativa, independentemente da natureza da decisão, elas envolvem o método econômico (GICO JÚNIOR, 2012, p. 13) ${ }^{11}$.

Com este enfoque a análise econômica oferece instrumentos úteis ao mundo jurídico, pois calcada em uma teoria sobre o comportamento humano que inexiste no Direito. Auxilia, assim, na compreensão dos fatos sociais, seja através de um diagnóstico da realidade objetiva (análise positiva), seja por meio uma prognose (análise normativa) de como os agentes responderão a determinados incentivos legais (GICO JÚNIOR, 2012, p. 18).

A metodologia Econômica aplicada ao Direito deve responder, em resumo, a quatro perguntas básicas em relação ao ordenamento jurídico:

1) qual o objetivo a ser alcançado com determinada norma jurídica?

2) a norma jurídica atinge os resultados esperados?

3) quais as consequências da aplicação da norma jurídica?

4) como a norma jurídica deveria ser aplicada?

\section{PREMISSAS METODOLÓGICAS DA AED}

Para trazer respostas a tais indagações, o método econômico encontra-se amparado em algumas premissas ou postulados que fornecem uma estrutura teórica ao modelo. São eles: a) a escassez dos recursos, b) a racionalidade dos agentes, c) os incentivos ofertados e d) a eficiência econômica.

O primeiro deles retrata um dilema marcado pela dicotomia entre a escassez de recursos frente à ilimitação das necessidades humanas. De fato, os desejos hauridos do coração humano não possuem limites ao contrário dos recursos, que são finitos por natureza. A lei da escassez é uma constância do qual o homem, ainda que tente superar, não pode escapar (NUSDEO, 2008, p 27) $)^{12}$.

11 "Nesse sentido, a ciência econômica, antes associada apenas àquela parte da atividade humana que chamamos normalmente de economia, hoje investiga um amplo espectro de atividades humanas, muitas das quais também são estudadas por outras ciências sociais como a ciência política, a sociologia, a antropologia, a psicologia e, como não poderia deixar de ser, o direito. É essa interação entre direito e economia que se convencionou chamar de Análise Econômica do Direito".

12 "Ao oposto do que ocorre com as necessidades humanas, os recursos com que conta a humanidade para satisfazê-las apresentam-se finitos e seriamente limitados. Tal limitação é insuperável, malgrado os sucessos da tecnologia em empurrar sempre adiante o ponto de ruptura, quando do exaurimento dos bens disponíveis à espécie humana levaria, senão ao colapso, pelo menos à progressiva estagnação de todo o processo econômico, o qual, em última instância, consiste na administração dos recursos escassos à disposição dos habitantes deste planeta. (...) A lei da escassez é uma lei férrea e 
Houvesse, pois, recursos em abundância não haveria atritos sociais. Não existiria nenhuma lide, enquanto conflito qualificado de interesses, tornando, então, tanto o Direito, quanto a Economia, desprovidos de sentido.

Por ilação, é em razão da insuficiência de bens que se impõe a todos um processo de escolha entre as alternativas possíveis, mas excludentes entre si.

O processo de tomada de decisão parte, assim, de um segundo pressuposto, qual seja, de que os agentes econômicos são racionais.

A racionalidade maximizadora representa, dentro da escassez de recursos, a tentativa de promoção do auto interesse (SMITH, 2019) ${ }^{13}$, isto é, pressupõe que os indivíduos ajam visando satisfazer os seus objetivos pessoais, sejam eles quais forem.

Esse modelo decisório maximizador do próprio interesse, por assim dizer, abrange as mais imaginosas ações humanas, desde a realização de atividades econômicas e até os processos de escolhas mais simples, como a decisão de consumo ou o lazer e, ainda, as mais elaboradas decisões como a celebração de contratos e o aforamento de litígios (SALAMA, 2017 , p. 27$)^{14}$.

Fique claro que esse approach econômico não se confunde com egoísmo ou ganância. A juseconomia não se destina a ganhos materiais, mas se concentra em como as pessoas se comportam visando satisfazer a seus próprios interesses ou maximizar as suas preferências pessoais.

Em outros termos, as pessoas agem de modo atingir utilidades pessoais, independentemente de qual objeto for, seja pecuniário, político, altruísta ou até mesmo familiar (GICO JÚNIOR, 2012, p. 23) ${ }^{15}$.

Adota-se a imagem do homo economicus ancorada na filosofia do utilitarismo (BENTHAM, 1984, p. 09-13) ${ }^{16}$.

Sob o amálgama deste princípio as decisões humanas passam a ser encaradas como resultante de um processo mental calculado, no qual a pessoa pondera, tal qual um contador, os ganhos a serem obtidos de sua conduta, deduzido de eventuais perdas a serem evitadas, maximizando o gozo das utilidades a ponto de se traduzir em bem-estar e felicidade (HUNT.; LAUTZENHEISER, 2013, p. 193-194).

incontornável, tendo submetido os homens ao seu jugo desde sempre, levando-os a se organizarem e a estabelecerem entre si relações específicas, a fim de enfrentá-la, ou melhor, conviver com ela, atenuando-lhe, o quanto possível, a severidade".

13 Como já prenunciava Adam Smith: "Não é da benevolência do açougueiro, do cervejeiro e do padeiro que esperamos o nosso jantar, mas da consideração que eles têm pelos próprios interesses. Apelamos não à humanidade, mas ao amor-próprio, e nunca falamos de nossas necessidades, mas das vantagens que elas podem obter".

14 "Esse comportamento maximizador é, portanto, tomado como abrangendo uma enorme gama de ações, que vão desde a decisão de consumir ou produzir um bem, até a decisão de contratar com alguém, de pagar impostos, de aceitar ou propor um acordo em um litigio, de falar ao telefone celular ao dirigir e, até mesmo, de votar contra ou a favor de um projeto de lei".

15 "(...) a abordagem juseconômica não requer que se suponha que os indivíduos são egoístas, gananciosos ou motivados apenas por ganhos materiais, tão somente assume-se que os agentes são racionais maximizadores de sua utilidade, seja lá o que isso significa para eles. Nessa linha, por exemplo, são plenamente passíveis de análise econômica situações em que o comportamento humano tenha como motivação central elementos imateriais ou psicológicos, como prestígio (e.g., academia), poder (e.g., política) ou mesmo altruísmo (e.g., família). Ainda assim, é o indivíduo quem age e a partir dele iniciamos nossa busca pela compreensão do coletivo".

16 Jeramy Bentham é considerado o grande precursor do princípio da utilidade, no sentido de que pessoas buscam maximizar o seu próprio bem-estar reconhecendo que o gênero humano está sob o domínio de dois senhores: o prazer e a dor. Logo, é no desejo de obter felicidade e se afastar da dor que se pode encontrar a chave da motivação humana. 
Esse ideal racional, calcado na escolha de alternativas que se excluem mutuamente, em virtude da restrição de recursos, enseja uma análise comparativa entre o custo e o benefício a ser obtido com o comportamento empenhado, o que em linguagem econômica se traduz pela expressão trade-off.

Vale dizer, para se obter algo é preciso abrir mão de outro, em uma relação de perda e ganho. Em outras palavras, o deleite de qualquer benefício enseja a renúncia do equivalente não escolhido ou preterido. A vida, portanto, passa ser encarada como um processo permanente de trocas, seja com preços explícitos ou não (GICO JÚNIOR, 2012, p. 20) ${ }^{17}$.

Aqui repousa o aspecto fundamental do modelo comportamental da Economia aplicado ao Direito. Utiliza-se como ponto de partida o individualismo metodológico, por meio da dedução de que o comportamento individual maximizador de sua utilidade seja projetado coletivamente nas empresas, organizações, instituições e no próprio Estado.

Como desdobramento correlato surge a questão de que toda conduta humana responde a incentivos. Eis o terceiro postulado da AED.

A ideia de incentivo é algo comum tanto no Direito, quanto na Economia. Todo o edifício jurídico é construído sobre a premissa de que as pessoas observarão as normas jurídicas, ou seja, responderão aos incentivos legais, positivos (prêmio) ou negativos (sanção), a depender do sopesamento marginal dos custos e benefícios que do comportamento deriva.

Transportado esse pensamento ao mundo jurídico, a conduta de cumprir ou não um contrato, violar a lei, cometer infrações civis ou penais dependerá, justamente, do balanço racional do indivíduo, acerca dos incentivos ofertados, sobre os custos ou os benefícios de que cada ação resultará (PINHEIRO; SADDI, 2005, p. 90) ${ }^{18}$.

$\mathrm{Na}$ economia não é diferente, tendo, porém, o foco dos incentivos na figura dos preços. Logo, se presume que as pessoas reajam às sanções legais, tais como os consumidores e agentes se portariam em relação aos preços de mercado. Se baixo, o comportamento será incentivado com a ampliação da oferta. Se alto, a tendência é de retração dela com o aumento do custo, o que inibirá o comportamento, dada a racionalidade dos agentes.

\section{COOTER e ULEN (2010, pag. 25) sintetizam a questão da seguinte maneira:}

Os legisladores muitas vezes perguntam: Como uma sanção vai afetar o comportamento? Por exemplo, se indenizações punitivas são impostas ao fabricante de um produto defeituoso, o que acontecerá com a segurança e o preço do produto no futuro? Ou, a criminalidade vai diminuir se os delinquentes que violam a lei pela terceira vez forem presos automaticamente? Os

17 "Toda escolha pressupõe um custo, um trade off, que é exatamente a segunda alocação factível mais interessante para o recurso, mas que foi preterida. A esse custo chamamos de custo de oportunidade. Assim, por exemplo, se decidimos comprar caças para fortalecer nossa Aeronáutica, abdicamos de outra alocação que estes recursos poderiam ter (e.g., construir escolas). Se você opta por ler este capítulo, deixa de realizar outras atividades como estar com seus filhos, passear com sua namorada ou assistir televisão. A utilidade que cada um gozaria com uma dessas atividades é o seu custo de oportunidade, i.e., o preço implícito ou explícito que se paga pelo bem. Note que dizer que algo tem um custo não implica afirmar que tem valor pecuniário. Agora você sabe que há muita sabedoria no dito popular "tudo na vida tem um preço", basta olhar para o lado".

18 "Aplicada ao universo do Direito, ela implica que a decisão de rescindir um contrato, de engajar-se em atividades originalmente não previstas no contrato, ou de comportar-se ilicitamente, dependerá de um balanço racional dos benefícios e custos marginais de cada ação. Por exemplo, o custo dos acidentes. 0 condutor do veículo só respeita a norma de parar em sinal vermelho porque isso é mais econômico do que receber uma multa de trânsito. Aqueles que violam a lei ou os contratos, segundo essa premissa conceitual, o fazem com o objetivo de maximizar a sua satisfação líquida, pois percebem benefícios superiores aos custos, entendidos de modo amplo para incluir a utilidade negativa resultante da perda da liberdade, do ostracismo social etc.". 
juristas responderam a essas perguntas em 1960 mais ou menos da mesma maneira que o tinham feito a 2 mil anos antes - consultando a intuição e quaisquer fatos que estivessem disponíveis. A economia proporcionou uma teoria científica para prever os efeitos das sanções legais sobre o comportamento. Para os economistas, as sanções se assemelham aos preços, e, presumivelmente, as pessoas reagem às sanções, em grande parte, da mesma maneira que reagem aos preços. As pessoas reagem mais altos consumindo menos do produto mais caro; assim, supostamente elas reagem a sanções legais mais duras praticando menos a atividade sancionada. A economia tem teorias matematicamente precisas (teoria do preço e teoria dos jogos) e métodos empiricamente sólidos (estatísticas e econometria) da análise dos efeitos dos preços sobre o comportamento.

A estrutura de incentivos, portanto, é a peça essencial na compreensão da Análise Econômica do Direito. A mudança do comportamento social, por meio das regras jurídicas, depende justamente dos incentivos adotados na norma, seus objetivos e resultados que podem ser avaliados concretamente pela leitura econômica ${ }^{19}$.

Com este norte, um sistema legal deve estar mais preocupado com a estrutura dos incentivos do que com valores abstratamente considerados, a fim de que se alcancem os objetivos almejados.

Diante de todo esse panorama de escassez, racionalidade, maximização de utilidades e relações comparativas de custo-benefício a induzir escolhas e comportamentos, a análise econômica prima por uma alocação eficiente dos recursos disponíveis. A eficiência, pode se dizer, constitui o âmago ou pedra de toque da AED.

Em economia este postulado conduz a resultados amplos. A eficiência almeja a maximização da utilidade ou do bem-estar social e a minimização dos custos sociais envolvidos, podendo ser entendida dentro de uma concepção individual e coletiva.

A primeira concepção de eficiência econômica coube a Vilfredo Pareto. Para este só haveria eficiência na alocação de recursos no mercado quando houvesse uma situação de equilíbrio nas transações. Isto é, a eficiência corresponderia a uma melhora de situação obtida entre os agentes econômicos, desde que não ensejasse nenhuma perda, diminuição ou piora para outrem (SALAMA, 2017, p. 86) ${ }^{20}$. Haveria, nesse quadro, uma alocação ótima de recursos, um "Ótimo de Pareto" ou um "Pareto-eficiente".

A grande crítica deste critério repousa no aspecto individualista, consensualista e na exigência de unanimidade em seu equilíbrio conformador, o que conduz a uma irreal aplicação de seus requisitos, dado que, em uma economia capitalista, as trocas podem ser desiguais, sendo possível que ocorram perdas entre as partes e efeitos indesejáveis projetados para terceiros.

19 Exemplo emblemático, como estrutura de incentivos normativos para a redução de acidentes no trânsito, é a chamada "Operação Lei Seca", decorrente da lei n. ${ }^{\circ}$ 9.503/97, que sofreu agravamentos ao longo do tempo. A legislação traz sérias penalidades administrativas (art. 165) e criminais (art. 306), vedando a condução de veículo automotor, sob a influência de álcool ou de outra substância psicoativa, com a imposição de perdas financeiras decorrentes de aplicação de multas, custo de oportunidade pela suspensão do direito de habilitação, além do desgaste emocional e gastos com a defesa criminal e eventual cumprimento de pena em caso de condenação.

20 "A concepção do economista italiano Vilfredo Pareto tinha em mira resolver uma questão oriunda da filosofia utilitária relativa ao problema de mensuração de felicidade ou bem-estar geral. Para que este fosse observado seria preciso que todos os participantes envolvidos na transação experimentassem uma melhora de situação, quando comparada às condições originais anteriores à relação. A felicidade ou bem-estar Paretiano impõe que todos ganhem, mas que ninguém suporte perdas". 
Critica-se o critério de Pareto, pois o mesmo não é isento de valoração subjetiva, o que impede uma análise objetiva. Pareto pauta a eficiência sob um viés subjetivo individual, ou seja, com relação ao bem-estar pessoal (em que o bem-estar social se confunde com o bem-estar individual), sendo que, dessa maneira, o critério de eficiência seria subjetivado, já que fincado na concepção de bem-estar de cada qual. Todavia, uma solução ótima depende do ponto de vista de cada parte.

Suprindo esta necessidade equalizadora foi desenvolvido, por Nicholas Kaldor e John Hicks o método da compensação. No critério de Kaldor-Hicks, a eficiência alocativa não resta escorada no consenso, tampouco exigem-se ganhos unânimes.

O que importa é que o benefício socialmente auferido (bem-estar geral) tenha o condão de suplantar as perdas com a possibilidade, em tese, de compensação dos prejuízos suportados pelos perdedores. Daí se chamar de "Pareto-Superior".

De fato, em um mundo real, de economia de trocas, o critério de Pareto não se mostra o mais adequado. 0 ideal de bem-estar não pode estar atrelado ao um processo de igualdade. Em sendo as pessoas maximizadoras do próprio interesse e havendo escassez de recursos na outra ponta, todo o ganho pode corresponder a uma perda hipotética ou real, atual ou futura, individual ou difusa para o sistema.

Com essa roupagem, o critério de eficiência econômica não pode restar assentado na ausência de perdas, pois elas naturalmente existem. Mas sim na possibilidade de compensação, onde os ganhos gerais suplantem as perdas, havendo a maximização da riqueza coletiva e o cumprimento dos ditames da Ordem Constitucional Econômica (MARTINS, 2017, p. $31)$.

Para o Direito, eficiência, tradicionalmente, sempre foi vinculada ao alcance de Justiça. O brocardo romano fiat justitia et pereat mundus bem espelha esta faceta, pelo que a Justiça não poderia ser medida ou quantificável, mas sentida.

Entretanto fazer Justiça ainda que o mundo pereça revela um descompromisso total com a realidade social que nos circunda. $O$ velho adágio se esquece que os direitos têm custos, não nascem em árvores.

Em verdade, Justiça enseja valor. Nesse espectro, o ferramental econômico não pode radiografar essa valoração de modo fidedigno. Não pode dizer o que seja justo.

Todavia, em um cenário de escassez de recursos, com a necessidade constitucional de concretização de direitos fundamentais de toda espécie, uma norma jurídica que gere desperdícios, perdas injustificadas e desatendimento às legítimas pretensões, pode ser acoimada de injusta e, portanto, de ineficiente.

Nesse sentido a lição de GICO JUNIOR (2012, Pag. 27):

Em um mundo onde os recursos são escassos e as necessidades humanas potencialmente ilimitadas, não existe nada mais injusto do que o desperdício. Nesse sentido, a AED pode contribuir para (a) a identificação do que é injusto - toda regra que gera desperdício (é ineficiente) é injusta, e (b) é impossível qualquer exercício de ponderação se quem o estiver realizando não souber o que está efetivamente em cada lado da balança, isto é, sem a compreensão das consequências reais dessa ou daquela regra. A juseconomia nos auxilia a descobrir o que realmente obteremos com uma dada polí- 
tica pública (prognose) e o que estamos abrindo mão para alcançar aquele resultado (custo de oportunidade). Apenas detentores desse conhecimento seremos capazes de realizar uma análise de custo-benefício e tomarmos a decisão socialmente desejável. (...). Como dito, se os recursos são escassos e as necessidades potencialmente ilimitadas, todo desperdício implica necessidades humanas não atendidas, logo, toda definição de justiça deveria ter como condição necessária, ainda que não suficiente, a eliminação de desperdícios (i.e., eficiência). Não sabemos o que é justo, mas sabemos que a ineficiência é sempre injusta, por isso, não consigo vislumbrar qualquer conflito entre eficiência e justiça, muito pelo contrário, uma é condição de existência da outra.

É graças a Análise Econômica que o conceito de eficiência, no âmbito do Direito, é realinhado ao viés consequencialista ${ }^{21}$. Em linguagem jurídica, cuida-se de uma funcionalização da eficiência com o escopo de que o sistema normativo possa atender às pretensões individuais e coletivas sem que se perca o norte da economicidade.

\section{CONCLUSÃO}

Como visto, Direito e Economia não vivem em mundos separados. São ciências sociais que se completam. Ambas possuem como foco a organização, a estabilidade e a eficiência do sistema.

Com efeito, se no passado seus conhecimentos se mantinham separados, em razão da especialização acadêmica e diversidade de objetos, atualmente, esse isolamento não tem mais razão de ser.

A tradicional concepção do Direito, influenciada pelo positivismo jurídico, forte na ideia da metodologia pura e neutralidade científica não há de prosperar modernamente frente à exigência de atendimento as novas demais sociais, dentro de um cenário de escassez de recursos.

Em reação a este panorama surge a jus economia, como fruto do pragmatismo filosófico e do realismo jurídico, originando o movimento da Análise Econômica do Direito.

A partir de suas premissas metodológicas se busca avaliar o sentido descritivo da norma jurídica em sua aplicação real, no que tange ao conteúdo e efeitos concretos, bem como estabelecer uma prognose de como a norma deveria ser elaborada/aplicada, a fim de se alcançar os objetivos almejados, tendo como norte a economicidade e a estrutura de incentivos.

21 Esse parece ser o novo horizonte da sistemática jurídica trazido no Decreto-lei 4.657/62 - Lei de Introdução às normas do Direito Brasileiro. A redação do art. 21 estabelece que: A decisão que, nas esferas administrativa, controladora ou judicial, decretar a invalidação de ato, contrato, ajuste, processo ou norma administrativa deverá indicar de modo expresso suas consequências jurídicas e administrativas. Já o art. 23 reza que: a decisão administrativa, controladora ou judicial que estabelecer interpretação ou orientação nova sobre norma de conteúdo indeterminado, impondo novo dever ou novo condicionamento de direito, deverá prever regime de transição quando indispensável para que o novo dever ou condicionamento de direito seja cumprido de modo proporcional, equânime e eficiente e sem prejuízo aos interesses gerais. 


\section{REFERENCIAS}

BENTHAM, Jeremy. Uma Introdução dos princípios da Moral e da Legislação.

Tradução: Luiz João Baraúna. 3ª ed. São Paulo: Abril Cultural, 1984.

BITTAR, Eduardo C. B.; ALMEIDA, Guilherme de Assis. Curso de Filosofia do Direito. 14 a ed. São Paulo: Atlas, 2019.

BURKE, Edmund. Frases. Disponível em: https://www.pensador.com/autor/edmund_burke/. Acesso em: 06 set. 2019.

CHAUI, Marilena. Convite a filosofia. Ed. Ática, São Paulo, 2000.

COELHO, Fabio Ulhoa. Para entender Kelsen. 4ª ed. São Paulo. Saraiva. 2001.

COOTER, Robert; ULEN, Thomas. Direito e Economia. Tradução: Luis Marcos Sander. $5^{\text {a }}$ ed. Porto Alegre: Bookman, 2010.

FONTES, Paulo Gustavo Guedes. Filosofia do Direito. $1^{\text {a }}$ ed. Rio de Janeiro: Forense, 2014.

GICO JÚNIOR, Ivo; Introdução ao Direito e Economia. In: TIMM, Luciano Benetti (Org.). Direito e economia no Brasil. São Paulo: Atlas, 2012

GODOY, Arnaldo Sampaio de Moraes. Embargos culturais - O realismo jurídico norte-americano é intrigante. Conjur. 2012. Disponível em: https://www.conjur.com.br/2012-jul-15/embargos-culturais-realismo-juridico-norte-americano-intrigante. Acesso em: 15 mai. 2019.

HUNT, E. K.; LAUTZENHEISER, Mark. História do pensamento econômico. Tradução de André Arruda Villela. Rio de Janeiro: Elsevier, 2013

LEWIS, Sandra Barbon. A íntima relação entre o direito e economia. Revista de Direito Mercantil, Industrial, Econômico e Financeiro, São Paulo, n. 138,_p. 231-249, abr./2005

NUSDEO, Fabio. Curso de economia: introdução ao direito econômico. 5 ed. rev. e atual. São Paulo: Ed. Revista dos Tribunais, 2008

MARTINS, Arthur Villamil. O empresário, a análise econômica e a eficiência. Revista da AMDE (Associação Mineira de Direito e Economia), Belo Horizonte, ano 2017, v. 17. Disponível em: http://www.revista.amde.org.br/index.php/ ramde/article/view/271. Acesso em: 19 jul. 2019.

PINHEIRO, Armando Castelar; SADDI, Jairo. Direito, Economia e Mercados. Rio de Janeiro: Elsevier. 2005.

POSNER, Richard. Economic Analysis of Law. 3ª ed. Wolters Kluwel, 1986.

REALE JUNIOR, Miguel. Lições preliminares de Direito. 27ª ed. São Paulo: Saraiva, 2002.

SALAMA, Bruno Meyerhof. Estudos em Direito e Economia. $1^{\text {a }}$ ed. Curitiba: Editora Virtual Gratuita. 2017. SMITH, Adam. Frases. Disponível em: https://kdfrases.com/frase/119296. Acesso em: 17 mai. 2019.

Recebido/Received: 30.04.2020.

Aprovado/Approved: 12.06.2020. 